\author{
Е. В. Рахилина, В. А. Плунгян ${ }^{2}$ \\ ${ }^{1}$ Институт русского языка им. В. В. Виноградова РАН \\ НИУ «Высшая школа экономики» \\ ${ }^{2}$ Институт русского языка им. В. В. Виноградова РАН \\ МГУ им. М.В. Ломоносова \\ (Россия, Москва) \\ rakhilina@gmail.com,plungian@iling-ran.ru
}

\title{
О ГЛАГОЛЕ ТАИТЬСЯ, ЕГО СИНОНИМАХ И ПРОИЗВОДНЫХ*
}

В статье рассматривается история семантической эволюции почти вышедшего из употребления русского глагола таиться и его префиксальных производных (затаиться, притаиться, утаиться). Показано, что значение этих глаголов в русском языке XVIII-XIX вв. в ряде отношений существенно отличалось от современного. Проведены наблюдения над параметрами, различающими квазисинонимы ряда со значением 'прятаться': прятаться и скрываться, уточнено место каждого из них на шкале контроля. Подробно проанализированы приставочные глаголы, производные от таиться, и на основе сделанных наблюдений описана диахроническая семантика этой сравнительно малочастотной лексической группы. Проведенное исследование обнаруживает свойственную этому ряду постепенную стативизацию, связанную с потерей агентивности и контролируемости, а также процесс лексикализации - «застывание» устаревающей лексемы в какой-то определенной словоизменительной форме или конструкции, которое приводит к значительному росту частотности практически вышедшего из употребления слова. Судьба таиться и близких ему лексем хорошо иллюстрирует общие исторические процессы, связанные со сдвигом лексического значения. Прежде всего это мотивированность семантической сочетаемости на каждом временно́м этапе, а также взаимозависимость лексических и грамматических свойств языковой единицы, которую может отразить только интегральное описание. Оба эти аспекта неразрывно связаны с вкладом Ю.Д. Апресяна в общую теорию языка.

Ключевые слова: диахроническая семантика, лексика, русский язык, глаголы, корпусные исследования, стативизация, лексикализация.

* Исследование осуществлено в рамках Программы фундаментальных исследований НИУ ВШЭ в 2020 году. 
Лищь тому, чей покой таим, Сладко дышится...

И. Анненский (1909)

А взволнованная кошка притаилась за кустом... Саша Черный (1921)

\section{о. Введение}

Всю свою историю общая лингвистика была не очень внимательна к лексическим сюжетам. Даже если ограничиться глагольной семантикой, которая, бесспорно, представляла самый большой интерес с теоретической точки зрения и которая подробнее всего описана в отношении лексико-семантических (таксономических) классов, сами классы, которые попали под сколько-нибудь пристальное наблюдение, в общем немногочисленны. Пожалуй, их даже не так трудно перечислить. Это глаголы движения, знания и мнения, желания, смены посессора, позиции и эмоций. Всех этих сюжетов касался в своих работах и Юрий Дереникович (в наиболее концентрированном виде анализ различных классов глагольной лексики представлен в обобщающем исследовании [Апресян 2009]). Но его идея интегрального описания языка предполагает, что практически любая лексема любого языка может представлять интерес с точки зрения своих свойств: ее языковое поведение мотивировано, с одной стороны, ее индивидуальной семантикой (и поэтому отличается от поведения квазисинонимов), а с другой - общесемантическими процессами, которые свойственны языку. Главное и убедительнейшее доказательство, которое он нам всем уже предъявил, - это научные проекты-словари под его редакцией — «Новый объяснительный словарь синонимов» (2004 г.) [НОСС] и «Активный словарь русского языка» (тт. 1-3, 2014-2017 гг.) [АС].

В этой маленькой заметке мы коснемся малочастотного (и в целом скорее уходящего из современного узуса), но во многих отношениях интересного глагола таиться (разделы 1 и 3), а также его семантических коррелятов, определяющих структуру противопоставлений в соответствующем семантическом поле: синонимов (раздел 2) и словообразовательных производных (раздел 4). Наша задача - выявить таящи еся в нем и его коррелятах свойства (они суммируются в разделе 5.1 заключения) и таин ст в нн ые процессы семантических сдвигов (раздел 5.2).

\section{1. О свойствах глагола таиться}

Согласно данным [НКРЯ], в современном языке глагол таиться употребляется только с абстрактными именами в качестве субъекта. Это обозначения свойств, состояний или абстрактных объектов, которые существуют, но могут быть недоступны наблюдателю, ср.: 
(1) ..глубокий смысл таится в этом сравнении и страшное пророчество... (Н. В. Устрялов. Судьба Петербурга. 1918) ( $\approx$ 'смысл существует, но не каждому он доступен').

Субъект глагола может соотноситься с чем-то полезным и функционально значимым (как ответ, причина, разгадка, истина, смысл), и в частности с желаемыми, но скрытыми свойствами (как богатство, талант, счастье, красота, силь, возможности), - или, напротив, с угрозой, с которой надо считаться, если она вдруг проявится (ср. опасность, зло, злоба, угроза, усмешка). Все это - ситуации, которые участник ситуации (носитель свойства) или внешний наблюдатель никак не контролируют. Если даже это внутренние возможности или свойства человека (как талант или красота), то человек, в котором они таятся, о них мало или вовсе не знает (а если бы знал, то вряд ли бы их таил). Обнаруживают и обсуждают их посторонние, как в (2):

(2) В ребенке - так полагали учителя - уже таятся силь, обеспечиваюшие духовное его развитие (Л.Р. Кабо. Ровесники Октября. 1964).

Впрочем, есть по крайней мере один распространенный контекст, в котором можно усматривать хотя бы слабое, но присутствие компонента намерения. Он связан с сокрытием своего страха. Бояться - стыдно, нужно быть храбрым и не подавать виду, что страшно, утаивая признаки страха:

(3) Где-то за умными и скептическими разговорами, вольными анекдотами maumcя страх (М. Поповский. Семидесятые. Записки максималиста. 1971); (4) Во всех этих слухах таился страх... (А.И. Алдан-Семенов. Красные и белые. 1966-1973).

Идея намеренного сокрытия эмоции - это след предшествующего семантического статуса глагола таиться. [СлРЯ XI-XVII] дает для него прежде всего контролируемые значения: ‘быть скрываемым' и 'скрываться; прятаться'. Оба эти значения таиться в современном языке исчезли, но могли провоцировать идею сознательного сокрытия. В основном корпусе [НКРЯ] они почти не представлены, ср. разве что пример (5), но в поэтическом корпусе, который хорошо отражает более раннюю норму, контексты контролируемого употребления можно найти, ср. (6)-(7):

(5) Любовники сколько ни таятся, все их изобличает (И. М. Долгоруков. Повесть о рождении моем... 1788-1822);

(6) Средь блат, в развалинах Карфаги Герой таится от врагов (Д.И. Хвостов. Позднее взывание к музе. 1822);

(7) Как птички при кустах таятся (Ю. А. Нелединский-Мелецкий. Свидетели тоски моей... 1796). 


\section{2. Таиться и его квазисинонимы: шкала контроля}

В целом похожее распределение значений характерно и для современных квазисинонимов таиться - глаголов скрываться и прятаться. Они тоже имеют контролируемые употребления (8)-(9) и наряду с ними неконтролируемые, с абстрактными субъектами (10)-(11) и конкретными пространственными объектами (12)-(13).

(8) Сейчас уже трудно пересказать этот сюжет... Засльишав свистки полицейских, он прятался в домике. Появлялись сами полицейские. Из домика выходил хозяин (И.Э. Кио. Иллюзии без иллюзий. 1995-1999);

(9) Я видел и оченил, и, смотав свое абордажное приспособление, довольный Табаки скрывается в дверях (М. Петросян. Дом, в котором... 2009);

(10) Разве ты не видишь: серые глаза, Только в самой дали прячется гроза (С. М. Городецкий. Серый вечер. 1907);

(11) ...под этой мягкостью скрывалась уверенность в своем достоинстве и никогда не высказывалась, а как-то видимо присутствовала в нем (И. А. Гончаров. Обрыв. 1869);

(12) B переулках те же хижины, большая часть на сваях, от сырости и насекомых. Хижины прячутся в бананнике и под пальмами кокоса и агеса (И. А. Гончаров. Фрегат «Паллада». 1855);

(13) Дно ее было глубоко внизу, а свод скрывался в клубивиихся в высоте золотиcmых облаках (А. М. Волков. Урфин Джюс и его деревянные солдаты. 1963).

Однако просто наличие похожих употреблений мало говорит о степени близости этих глаголов в узусе.

Начнем с того, что глагол таиться все-таки ощущается как литературный, и различие в его частотности по данным основного и газетного корпуса [НКРЯ] разительно. И, как мы помним, контролируемые ситуации для него все-таки практически недоступны.

Напротив, для прятаться именно они являются центральными, тогда как абстрактные субъекты при нем единичны и, как правило, сохраняют идею метафоры, фигуры речи, как в примере (10). В уже приведенных нами современных примерах поставить прятаться на место таиться не так просто, ср.: ?в сравнении прячется глубокий смысл, ?в ребенке прячутся < .. > сильл и т. п.; ср. также:

(14) Он знал, где таится ('прячется) преступление! В мозгу! (Ю. О. Домбровский. Факультет ненужных вещей. 1978).

Зато примеры со словом страх легко допускают замену таиться на прятаться - именно ввиду отмеченной выше скрытой намеренности, ср. вполне естественное за умныли разговорами прятался страх и др.

По сравнению с прятаться и таиться глагол скрываться гораздо более нейтрален: он плохо выглядит в примерах типа (14) - потому что, как и прятатьcя, переинтерпретирует их как намеренную ситуацию, однако достаточно частотен с абстрактной лексикой в неконтролируемых контекстах типа (11). 
Как видим, исходно все три глагола имели контролируемые употребления. Сейчас они образуют своего рода шкалу контроля: минимум контроля демонстрирует таиться, максимум - прятаться, а скрываться остается где-то в середине.

\section{3. Другие значения таиться}

[СлРЯ XI-XVII] отмечает еще одно значение маиться $^{1}$, не свойственное его квазисинонимам. В то время оно реализовывалось в конструкции с родительным: $X$ maumcя $Y$ - $a=$ 'Х держит в тайне свои мысли, чтобы не давать Ү-у к ним доступа', ср.:

(15) И кто будет верою огражен и в православии христианства крепок, и они того таятся, а ему таковы ся являют (XV в. 1487 г.).

Но уже словарные примеры XVI в. в аналогичных контекстах используют вместо беспредложного родительного предложную конструкцию с om. В примерах основного корпуса [НКРЯ] (с последней трети XVIII в.) тоже нет случаев управления родительным беспредложным, только родительным с предлогом om. Как свидетельствует корпус, со временем это значение подвергается лексикализации: таиться застывает в форме деепричастия таясь, отрицательно полярном. Например, в газетном корпусе оно выступает практически только в контексте отрицательной частицы - как не таясь в значении 'открыто, в открытую'. Не таясь живут, двигаются, разговаривают и смотрят:

(16) Были и дома, отмеченные зелеными крестиками. К таким они подъезжали в любое время, не таясь, и забирали коробки с детским питанием (М. Петросян. Дом, в котором... 2009);

(17) Мэбэт все больше впадал в досаду, оттого что нет у него сына, и, уже не таясь, говорил, что украдет себе другую жену, а ее прогонит, потому как не любил он, когда в становище много женщин (А. Григоренко. Мэбэт. 2011).

Таким образом, таиться не только уходит из языка, сокращая сочетаемость, но одновременно и закрепляется в нем в виде изолированного лексикализованного наречного оборота.

\section{4. Словообразовательные корреляты}

У таиться есть три приставочных коррелята, все совершенного вида: утаиться, притаиться и затаиться. Их распределение в основном и газетном корпусах [НКРЯ] примечательно. Наименее продуктивен утаиться - всего 75 вхождений

${ }^{1}$ На самом деле в словаре отмечено (хотя и слишком скупо проиллюстрировано) и еще одно полностью утраченное в литературном языке (начиная, по крайней мере, с XVIII в.) значение - 'действовать под видом другого лица', т. е. 'притворяться': «Посылаше царь князь великий до седмижды х казанцем послы своя, сам ходя с ними и речь их слушая, таяся, аки воин, а не царь, в простых же одежах» (XVI в.). 
в основном корпусе и три вхождения в газетном. В основном это старые примеры из известных авторов XIX-XX вв., описывающие контролируемые ситуации:

(18) И скользящим подозрительным взглядом окидывает комнату, не доверяя углам, где и собачонке-то не утаиться (А. Мариенгоф. Мой век, мои друзья и подруги. 1956-1960).

«Выживает» эта лексема, склонная к отрицательной полярности, за счет почти фразеологизованного не утаиться от $X$-а / взгляда (глаза) $X$-a, ср.:

(19) ...не утаится от зоркого писательского <..> взгляда (В.Д. Алейников. Тадзимас. 2002) $)^{2}$.

Притаиться довольно продуктивен (около 2000 вхождений в [НКРЯ]) и в основном описывает поведение людей в контролируемом значении 'спрятаться' - как раньше, так и теперь, (20)-(21), в том числе как живая метафора (22). Вместе с тем в газетном корпусе он встречается примерно в десять раз реже - это признак того, что и этот глагол постепенно уходит из языка.

(20) С Канаярнского острова увидел он девять турецких кораблей и несколько галер, идущих к Азову с подможным войском и с запасами. Петр повелел казакам притаиться (А. С. Пушкин. История Петра: Подготовительные тексты. 1835-1836);

(21) Совместный патруль притаился на улице Горького... (Комсомольская правда. 01.03.2011);

(22) Фальшь и подвох притаились повсюду (М. Давыдова. Известия. 23.05.2007).

Притаиться и затаиться кажутся очень близкими и по сочетаемости, и по семантике и в некоторых контекстах действительно взаимозаменимы:

(23) Я люблю твои лукавые глаза: Притаилася / ср.: затаилася в них молниягроза (В. В. Крестовский. Цыганке. 1863).

Однако прототипически притаиться выражает не только и не столько идею пассивного сопротивления возможной агрессии (= 'спрятаться в укромном месте и перестать подавать признаки жизни'), сколько подготовку к собственному (и скорее всего, агрессивному) действию, неожиданному для окружающих: “спрятаться так, чтобы в нужный момент неожиданно для контрагента выйти из укрытия и обнаружить себя'. В этом смысле притаиться - практически фазовый глагол, глагол подготовки к последующему действию.

Что касается затаиться, то этот глагол прототипически означает 'на время п ре кра т и т деятельность, которая протекала до этого', прекратить - спрятавшись и притихнув. Как видим, общего в семантике этих глаголов на самом деле не так уж много. Ср.:

${ }^{2}$ Ср. также употребительный фразеологизм шила в мешке не утаишь, существенно повышающий частотность каузативного коррелята утаиться. 
(24) Прошу вас, не надо съезжать по перилам, Вы можете в зубы попасть крокодилам! Они притаились (??затаились) на каждой площуадке И всех, кто съезжает, хватают за пятки (И. Токмакова. Крокодилы. 1965);

(25) Он притаился (??затаился) у подъезда, и, когда любовник вышел... Бац! Ему прямо в лоб (А. Сурикова и др. Ищите женщину. 1982);

(26) Ничего не усльхав и не поверив тишине, подумав, что враг затаился (= 'нападал, а потом перестал и спрятался', не *притаился), Тэдди опять прорычал, повернулся и стал уходить, все время оглядываясь. Но никто за ним не гнался (Ю. Казаков. Тэдди. 1956);

(27) Глухарь затаится (= 'перестанет токовать, замолкнет и станет как бы невидимым', не *притаится), пропустит тебя - и опять за свое примется (В. В. Бианки. Лесные были и небылицы. 1923-1958).

В этом отношении неслучаен тот сдвиг значения, который начинает развивать именно затаиться (но не таиться или притаиться) и который обнаруживается в современных (в особенности газетных) текстах. В процессе этого сдвига уходит идея зрительного / слухового восприятия и значение меняется с 'на время перестать быть физически видным / слышным' на функциональное 'перестать действовать, на время прекратить свою деятельность', ср.:

(28) Сразу после ограбления группа затаилась / *притаилась. Но спустя некоторое время они начали сбывать похищенные вещзи (Калининградские Новые колеса. 26.11.2004);

(29) ...пока инвесторы затаились в ожидании... (РБК Daily. 14.11.2008);

(30) Весь мир затаился в ожидании невиданных катастроф (Комсомольская правда. 29.02.2012);

(31) ...многие нечистые на руку милиционеры затаились, боясь не попасть в полицию, и на какое-то время перестали «подрабатывать» (РБК Daily. 27.03.2012).

\section{5. Заключение}

Как мы и обещали, в заключении будет два раздела: о свойствах таиться и его коррелятов (5.1) и о системных процессах, которые приводят к возникновению этих свойств (5.2).

5.1. В результате нашего исследования мы можем зафиксировать замеченные нами противопоставления в описываемом поле в нескольких очень предварительных и схематичных толкованиях ${ }^{3}$ и привести их временно́е распределение согласно [НКРЯ] (см. рисунок):

${ }^{3}$ Подчеркнем, что в наших толкованиях картина несколько упрощена: мы сознательно сосредоточились на центральных, прототипических употреблениях, которые задают своего рода семантический тренд, вектор развития для каждой из единиц, и проигнорировали проблему 


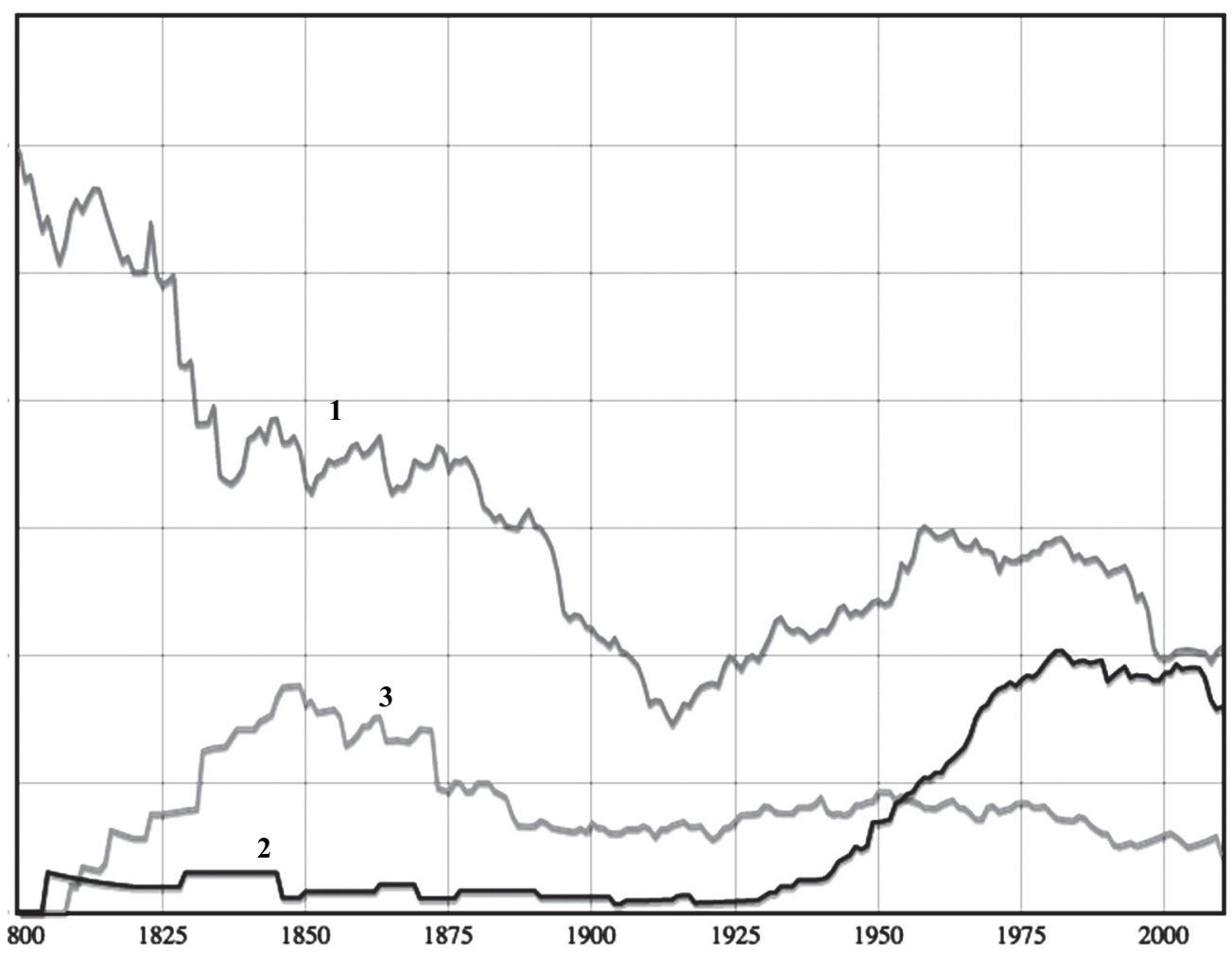

Рuc. График распределения частотности для таиться (1), затаиться (2) и притаиться (3)

- прятаться 'сознательно выбрать себе местоположение X с особыми свойствами, позволяющими реализовать цель, чтобы Ү не заметил и не нашел';

- скрываться 'менять местоположение так, что в результате становится трудно заметить / найти (а цели может не быть, как в он скрылся за дверью)';

- таиться 'не развиваться / проявляться, но иметь потенциал развития (о свойствах и абстрактных ситуациях)';

- притаиться 'находиться без движения в незаметном для окружающих месте, чтобы спрятаться от внешней агрессии или, наоборот, произвести неожиданное нападение на кого-либо';

- затаиться 'приложить усилия, чтобы (по некоторым причинам) на время перестать быть видимым, прекратить действовать'.

5.2. Развитие русского глагола таиться прекрасно иллюстрирует известный процесс стативизации, который свойственен многим глаголам, изначально описывающим контролируемые физические действия. Он сопровождается утратой

вариативности, которая в этой работе нас не так занимает. Между тем есть и характерные контексты пересечения значений, и вариативность в употреблении. 
контроля и постепенной полной заменой одушевленного субъекта субъектом неодушевленным или (как в случае таиться) абстрактным (субъектом-свойством / ситуацией). Другие примеры этого процесса касаются семантических переходов в глаголы боли, эмоции и др. (существенная их часть описана в [Падучева 2004; Кустова 2004]; специально о предикатах боли см. также [Бонч-Осмоловская и др. 2009]).

По-видимому, это общий путь развития глаголов этой группы в русском, просто сейчас разные предикаты находятся на разных его стадиях: таиться ушел далеко вперед, тогда как прятаться находится как бы на другом полюсе. Это по-прежнему агентивный глагол, хотя и с достаточно широкими возможностями метафорического применения к неодушевленным предметам и ситуациям. Скрываться же пока в равной степени способен принимать и контролируемые, и неконтролируемые субъекты. Промежуточность его положения сказывается, в частности, в том, что и с одушевленным субъектом он может обозначать ненамеренные ситуации, когда эффект исчезновения из поля зрения окружающих происходит случайно, в результате обычных его передвижений (скрылся за дверью).

Казалось бы, все фазы продвижения по шкале контролируемости в русском оказываются (в результате понятных и универсальных семантических изменений) полностью покрыты этими тремя глаголами — и тем не менее в нем полноценно функционируют еще два предиката, словообразовательные производные от таиться: притаиться и затаиться. Они компенсируют видовую дефектность таиться (только несовершенный вид) собственной (только совершенный вид). Очень огрубляя (и сводя приставочную производность к видовой парности), можно назвать их фазовыми и сказать, что первый из них - начинательный, а второй глагол прекращения действия. Однако их семантика и их (кажущаяся) видовая парность устроены не так просто.

Притаиться означает не начало, а подготовку к началу некоторого (агрессивного) действия, а затаиться - вре́менное прекращение деятельности. Средством и к тому и к другому служит намеренное исчезновение из поля зрения (и слуха) окружающих: спрятаться (из поля зрения) и не шуметь, сидеть тихо (на слух). В первом случае - чтобы создать последующий эффект неожиданности, а во втором - чтобы имитировать невозможность продолжения действия ввиду отсутствия субъекта.

Намеренность сближает эти глаголы с прятаться и семантически отдаляет от исходного таиться. Однако их формальная связь с таиться, конечно, остается - не исключено, что сужение его сочетаемости влияет и на сокращение узуса его производных. Однако частотность затаиться растет. Это показывает и график [НКРЯ], и значительное число употреблений в газетном корпусе. Лингвистический процесс, который стоит за этим ростом, можно было бы назвать в традиционных терминах обобщением значения. Однако механизм его тот же, что действует и при сужении значения таиться: и здесь, и там стирается физическая, зрительная, перцептивная сторона связанного с самим процессом исчезновения субъекта. Только в случае с таиться это вызывает замену 
контекстов с наблюдаемым субъектом-человеком на абстрактный субъект-ситуацию (а это существенно сужает его сочетаемость), а в случае с затаиться происходит постепенный переход от идеи (временного) прекращения некоего конкретного физического воздействия со стороны субъекта на (временное) прекращение его функционирования в целом (что по понятным причинам расширяет узус глагола).

История таиться иллюстрирует и другой характерный для полнозначных слов исторический процесс: их лексикализацию в определенной форме или конструкции, типологически описанную в [Brinton, Traugott 2005]. Он всегда приводит к росту частотности уходящего глагола. В данном случае таиться семантически «застывает» в форме деепричастия, причем отрицательно полярной, в фиксированном адвербиальном значении, выходящем, однако, за пределы грамматического набора. Это не случайно: в целом отрицательная полярность - известный стимул для лексикализации [Апресян 2017]. Так же ведет себя и уходящий глагол уmaиться, только он застывает в модальной конструкции со значением возможности, но тоже отрицательно полярной (<ничто> не утаится / <ничего> нельзя утаить). Понятно, почему лексикализация так удачно иллюстрируется таить: наиболее естественна она именно для тех слов, которые постепенно теряют частотность и, соответственно, степень освоенности носителями: их легче воспринять как новые самостоятельные единицы.

\section{Литература}

Апресян В.Ю. Отрицательная и положительная поляризация: семантические источники // Компьютерная лингвистика и интеллектуальные технологии : сб. ст. по материалам ежегодной международной конференции «Диалог-2017». Вып. 16 (23) / гл. ред. В. П. Селегей. М. : Изд-во РГГУ, 2017. С. 2-16.

Апресян Ю. Д. Исследования по семантике и лексикографии. Т. 1 : Парадигматика. М. : Языки славянских культур, 2009. 568 с.

АС - Апресян Ю.Д., Апресян В. Ю., Бабаева Е. Э., Богуславская О. Ю., Галактионова И. В., Гловинская М.Я., Иомдин Б. Л., Крылова Т. В., Левонтина И. Б., Лопухина А.А., Птенцуова А.В., Санников А. В., Урысон Е.В. Активный словарь русского языка / отв. ред. акад. Ю.Д. Апресян. Т. 1 : А-Б . 408 с. ; Т. 2 : В-Г. 736 с. М. : Языки славянских культур, 2014 ; Т. 3 : Д-3. М. ; СПб. : Нестор-История, 2017. $768 \mathrm{c}$.

Бонч-Осмоловская А. А., Рахилина Е.В., Резникова Т. И. Глаголы боли: лексическая типология и механизмы семантической деривации // Концепт боль в типологическом освещении / ред. В. М. Брицын и др. Київ : Вид. дім Дмитра Бураго, 2009. C. 8-27.

Кустова Г.И. Типы производных значений и механизмы языкового расширения. М. : Языки славянских культур, 2004. 470 с.

HКРЯ - Национальный корпус русского языка [Электронный ресурс]. URL: http://ruscorpora.ru 
НОСС - Апресян Ю.Д., Апресян В.Ю., Бабаева Е. Э., Богуславская О. Ю., Галактионова И. В., Гловинская М.Я., Иомдин Б. Л., Крылова Т.В., Левонтина И. Б., Птенцова A.В., Санников А. В., Урысон Е.В. Новый объяснительный словарь синонимов русского языка / под общ. рук. акад. Ю. Д. Апресяна. 2-е изд., испр. и доп. М. ; Вена : Языки славянской культуры, 2004. 1418 с.

Падучева E. В. Динамические модели в семантике лексики. М. : Языки славянских культур, 2004. 610 с.

СлРЯ XI-XVII - Словарь русского языка XI-XVII вв. / гл. ред. С. Г. Бархударов, В. Б. Крысько и др. М. : Наука : Азбуковник, 1975-. Вып. 1-.

Brinton L.J., Traugott E.C. Lexicalization and Language Change. Cambridge : Cambridge University Press, 2005. 207 p.

\section{E. V. Rakhilina ${ }^{1}$, V.A. Plungian ${ }^{2}$}

${ }^{1}$ Vinogradov Russian Language Institute of the Russian Academy of Sciences National Research University "Higher School of Economics"

${ }^{2}$ Vinogradov Russian Language Institute of the Russian Academy of Sciences

Lomonosov Moscow State University

(Russia, Moscow)

rakhilina@gmail.com,plungian@iling-ran.ru

\section{THE VERB TAIT'SJA 'TO LURK,' ITS SYNONYMS AND DERIVATIVES}

The paper tracks the semantic evolution of the (largely obsolete) Russian verb tait'sja 'be hiding, be hidden, lurk' and its prefixed counterparts (as za-tait'sja, pri-tait'sja, $u$-tait'sja). It is demonstrated that $18^{\text {th }}-19^{\text {th }}$-century Russian tended to use this group of verbs in quite different contexts. We discuss the parameters differentiating lexical items belonging to a wider semantic series with the main component 'hide' (prjatat'sja and skryvat'sja) and specify their position along the scale of control. Then, we propose a detailed analysis for the prefixed counterparts of tait'sja and describe the diachronic semantics of this small lexical group. The study reveals a gradual stativization of meaning triggered by a loss of agentivity and control, as well as a lexicalization, i.e. a fossilization of an obsolete lexeme in a specific inflectional form or construction. The latter process results in an increased frequency of an otherwise disused item. The history of tait'sja and its relatives can serve as a good example of general diachronic principles relevant for semantic change. First of all, this is the maintenance of semantically motivated combinability in each diachronic stage, as well as the deep intertwining of lexical and grammatical properties captured by an integral linguistic description. Both principles are crucial for Jurij Apresjan's contribution to the general theory of language.

Key words: diachronic semantics, lexicon, Russian, verbs, corpus linguistics, stativization, lexicalization. 


\section{Acknowledgements}

The research has been supported by the Higher School of Economics basic research Program in 2020.

\section{References}

Apresyan V.Yu. [Negative and Positive Polarization: Semantic Sources]. Komp'yuternaya lingvistika i intellektual'nye tekhnologii: sb. st. po materialam ezhegodnoi mezhdunarodnoi konferentsii «Dialog-2017». Vyp. 16 (23) [Computer Linguistics and Intelligent Technologies: A Collection of Articles Based on the Materials of the International Conference Dialog-2017. Iss. 16 (23)]. V.P. Selegei. Moscow, Russian St. Univ. for the Humanities Publ., 2017, pp. 2-16. (In Russ.)

Apresyan Yu.D. Issledovaniya po semantike i leksikografii. T. 1: Paradigmatika [Research on Semantics and Lexicography. Vol. 1: Paradigmatics]. Moscow, Yazyki slavyanskikh kul'tur Publ., 2009, 568 p.

Apresyan Yu.D., Apresyan V.Yu., Babaeva E.E., Boguslavskaya O.Yu., Galaktionova I.V., Glovinskaya M.Ya., Iomdin B.L., Krylova T.V., Levontina I.B., Lopukhina A. A., Ptentsova A.V., Sannikov A.V., Uryson E. V. Aktivnyi slovar' russkogo yazyka [Active Dictionary of the Russian Language] (Vols. 1-3). Yu.D. Apresyan (Ed.). Moscow, St Petersburg, Yazyki slavyanskikh kul'tur Publ., 2014-2017.

Apresyan Yu.D., Apresyan V.Yu., Babaeva E.E., Boguslavskaya O.Yu., Galaktionova I. V., Glovinskaya M.Ya., Iomdin B. L., Krylova T. V., Levontina I. B., Ptentsova A. V., Sannikov A. V., Uryson E. V. Novyi ob"yasnitel'nyi slovar' sinonimov russkogo yazyka [The New Explanatory Dictionary of Russian Synonyms] ( $2^{\text {nd }}$ Ed.). Yu.D. Apresyan (Ed.). Moscow, Vienna, Yazyki slavyanskoi kul'tury Publ., 2004. 1418 p.

Bonch-Osmolovskaya A.A., Rakhilina E.V., Reznikova T.I. [The Verbs of Pain: Lexical Typology and the Mechanisms of Semantic Derivation]. Kontsept «bol'»v tipologicheskom osveshchenii [The Concept of Pain in the Light of Typology]. V. M. Britsyn et al. (Eds.). Kiev, Dmitry Buryi Publ. House, 2009, pp. 8-27. (In Russ.)

Brinton L. J., Traugott E.C. Lexicalization and Language Change. Cambridge, Cambridge University Press, 2005, 207 p.

Kustova G.I. Tipy proizvodnykh znachenii i mekhanizmy yazykovogo rasshireniya [The Types of Derivative Meanings and the Mechanisms of Language Extensions]. Moscow, Yazyki slavyanskikh kul'tur Publ., 2004, 470 p.

Natsional'nyi korpus russkogo yazyka [The National Corpus of the Russian Language]. Available at: http://ruscorpora.ru

Paducheva E. V. Dinamicheskie modeli v semantike leksiki [Dynamic Models in Lexical Semantics]. Moscow, Yazyki slavyanskikh kul'tur Publ., 2004, 610 p.

Slovar' russkogo yazyka XI-XVII vv. [The Russian Language Dictionary of the $11^{\text {st }}$ $17^{\text {th }}$ c.] (Vols. 1-). S. G. Barkhudarov, V.B. Krys'ko et al. (Eds.). Moscow, Nauka Publ., Azbukovnik Publ., 1975-. 